\title{
Impact of Intrauterine Growth Restriction Diseases on The Umbilical Cord Blood CD34+ Cell Counts
}

\begin{tabular}{|c|c|}
\hline Author(s) & 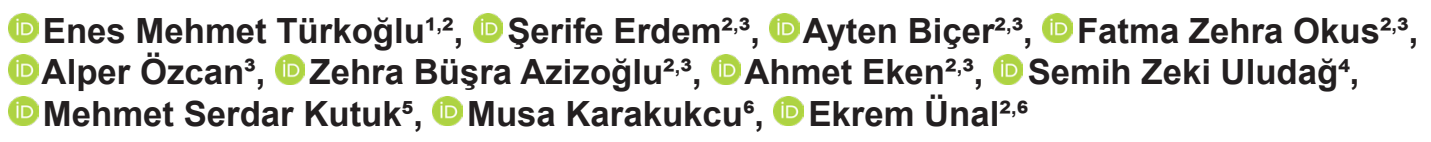 \\
\hline Affiliation(s) & $\begin{array}{l}\text { 'Erciyes University School of Medicine, Kayseri, Turkey } \\
\text { 'Betül-Ziya Eren Genome and Stem Cell Center (GENKOK), Kayseri, Turkey } \\
\text { 'Erciyes University School of Medicine, Medical Biology Department, Kayseri, Turkey } \\
\text { "Department of Obstetrics and Gynecology, School of Medicine, Erciyes University } \\
\text { "Department of Obstetrics and Gynecology, Medical Faculty, Bezmi Alem University, Istanbul, Turkey. } \\
\text { 5Department } \\
{ }^{6} \text { Erciyes University School of Medicine, Pediatric Hematology-Oncology Department, Kayseri, Turkey }\end{array}$ \\
\hline $\begin{array}{c}\text { Article } \\
\text { Information }\end{array}$ & $\begin{array}{l}\text { Article Type: Original Article } \\
\text { Article Group: Pediatric Hematology-Oncology }\end{array}$ \\
\hline
\end{tabular}

\section{Abstract}

Different diseases in obstetrics and gynecology can affect the number of CD34+ cells in the umbilical cord blood. This study aimed to evaluate the effect of Gestational Diabetes Mellitus (GDM), Gestational Hypertension (GHT) and Morbidly Adherent Placenta (MAP) on the content of CD34+ cells of umbilical cord blood and to compare the effectiveness of Sysmex XN20 analyzer to the flow cytometry method, which is the gold standard in CD34+ cells. The umbilical cord blood $(15 \mathrm{ml})$ was collected after the birth of the newborns. Peripheral blood mononuclear cells (PBMCs) were isolated by Ficoll-Paque Plus. The cells were stained with Procount TM Progenitor Cell Count Kit with PE Labeled monoclonal anti-CD34+ antibody then analyzed with Flow Cytometry or Sysmex XN20 without staining, to identify CD34+ cells named as hematopoietic progenitor cells (HPC), respectively.Flow cytometric evaluation revealed a significantly elevated $(p<0.05)$ number of cord blood CD34+ cells in GDM and GHT groups compared with healthy controls. MAP patients had comparable CD34+ cells compared with healthy controls. A significant increase in lymphocyte counts was also observed in GDM and GHT groups compared with healthy controls. Sysmex analysis however only revealed an increase in lymphocyte numbers in GHT but picked no differences across groups in HPC. Correlation between Sysmex and flow cytometry results was weak in control, GHT, GDM and MAP groups r: 0570/p<0.01, r: 0.5727/p: 0.0708, r:0.2149/p: 0.4779, r: 0.111/p: 0.779, respectively. CD34+ cells were significantly higher in the GHT and GDM groups compared with healthy control cord blood. The correlations between Flow cytometry and Sysmex were not strong.

Keywords: CD34+ cells, gestational hypertension, gestational diabetes, morbidly adherent placenta, umbilical cord blood

Correspondence: Ekrem Unal, Erciyes University Medical Faculty, Pediatric Hematology Oncology Division, Kayseri, Turkey

E-mail: drekremunal@yahoo.com.tr 


\section{Introduction}

Stem cells are self-renewing cells that can differentiate into specialized cells. Hematopoietic stem cells (HSC) $\mathrm{s}$ can be obtained from bone marrow (BM) aspirates, mobilized peripheral blood, and umbilical cord blood. ${ }^{1}$ HSCs transplantation is an important treatment alternative for hematological, genetic, malignant, neurological, and autoimmune diseases. Recently, there has been an increasing interest in umbilical cord blood transplantation due to its advantages over bone marrow. Umbilical cord blood offers less restrictive criteria for HLA matched donor and has a reduced risk of chronic and acute graft versus host disease (GVHD) due to its naive lymphocyte structure..$^{2,3}$ Practical advantages

Highlight
- CD34 + cells in the umbilical cord
blood were significantly elevated in
patients with gestational diabetes and
gestational hypertension
- No change was observed in patients
with morbidly adherent placenta
include the abundant supply of donors without any risk, as well as the presence of frozen graft in emergencies such as COVID-19 pandemic, and the less possibility of transmitting infectious agents to the recipient. ${ }^{4,5}$

The success of umbilical cord blood transfusion is associated with the number of total nucleated cells (TNCs) and CD34+ cells transmitted, but insufficient amounts of HSCs in umbilical cord blood are associated with poor recovery, especially in adults and older children those weighs more than $30 \mathrm{~kg}$ so this factor is one of the most important barriers to the spread of umbilical cord blood transplantation. ${ }^{6-8}$ Because of these restrictive problems, research in the literature has focused on factors altering CD34+ cells product such as maternal age, smoking status, birth weight, gestational age, gender, mode of delivery, preeclampsia. ${ }^{9-12}$ Whereas the effect of morbidly adherent placenta (MAP) disease caused by abnormal implantation of the basal plate, ${ }^{13}$ reported as $3 \%$ in women with previous cesarean history and $60 \%$ in women with three previous cesarean histories, MAP's impact on CD34+ cells ${ }^{14}$ has not been demonstrated. 15 Also, there are not many articles on the effect of gestational diabetes mellitus (GDM) and gestational hypertension (GHT) diseases on the number of CD34+ cells in the umbilical cord blood, which are important diseases in obstetrics and gynecology practice.
The purpose of this study was to investigate the impact of GDM, GHT, and MAP on CD34+ cells count in umbilical cord blood, and additionally, to compare the Sysmex XN20, automated Hematology Analyzers to the gold standard test of Flow Cytometry in the context of these diseases.

\section{Materials and Method}

\section{Study Subject}

Informed consent information was obtained from all pregnant women participating in the study and the research protocols were approved by the Ethics Committee at Erciyes University (Approval date/number: 2018/608). The study population consisted of 18 control pregnant without any underlying disease, 9 MAP, 13 GDM and 11 GHT patients. The delivery type of all of the people in the study is cesarean section. The diagnosis of GDM has been established according to the 75-gram oral glucose tolerance test of American Diabetes Association (ADA). The diagnosis of subtitles of gestational hypertension such as preeclampsia was made according to the American College of Obstetrics and Gynecology (ACOG). The clinical classification of the study population was shown in (Table 1).

\section{Umbilical cord blood samples}

This is an experimental study carried out on the umbilical cord blood sample which was collected in the delivery room in Gevher Nesibe Medical Faculty, Erciyes University. All blood samples were taken from the umbilical cord after delivery of newborn into EDTA anticoagulated blood tubes. Cord blood samples delivered to the laboratory within 24 hours were processed for mononuclear cell (MNC) isolation using a Ficoll-Paque Plus based on the manufacturer's instructions. After the procedure, the isolated cells were frozen until the sample collection was completed.

\section{HPCs and CD34+ cells enumeration}

Frozen PBMCs were resuspended in PBS (500 $\mu \mathrm{l})$ and HPC was quantified via Sysmex XN20 (Sysmex

\begin{tabular}{|c|c|c|c|c|c|c|c|}
\hline & \multirow{2}{*}{$\begin{array}{c}\text { Control group } \\
(n=18)\end{array}$} & \multicolumn{2}{|c|}{ GDM $(n=13)$} & \multicolumn{2}{|c|}{$\begin{array}{l}\text { Gestational hypertension } \\
(n=11)\end{array}$} & \multicolumn{2}{|c|}{ MAP $(n=9)$} \\
\hline & & $\begin{array}{l}\text { Mean } \pm \text { SEM } \\
\text { or } \mathrm{N}(\%)\end{array}$ & $p$ value & $\begin{array}{l}\text { Mean } \pm \text { SEM } \\
\text { or } \mathrm{N}(\%)\end{array}$ & $p$ value & $\begin{array}{l}\text { Mean } \pm \text { SEM } \\
\text { or } \mathrm{N}(\%)\end{array}$ & $p$ value \\
\hline Maternal age (years) & $30.70 \pm 1.438$ & $33.64 \pm 1.527$ & 0.3686 & $33.27 \pm 1.402$ & 0.4778 & $33.70 \pm 1.274$ & 0.3766 \\
\hline Gestational age (days) & $269.9 \pm 1.442$ & $263.4 \pm 2.129$ & 0.0855 & $262.9 \pm 2.862$ & 0.0601 & $249.8 \pm 2.843$ & $<0.001^{*}$ \\
\hline Birth Weight (g) & $3394 \pm 115.4$ & $3281 \pm 158.9$ & 0.9192 & $2800 \pm 203.6$ & $0.0179 *$ & $2886 \pm 158.5$ & 0.0602 \\
\hline \multicolumn{8}{|l|}{ Neonatal gender } \\
\hline Male & $10(\% 50)$ & $7(58.3)$ & 0.944 & $6(\% 50)$ & $>0.9999$ & $8(88.8)$ & 0.1035 \\
\hline Female & $10(\% 50)$ & $5(41.7)$ & & $6(\% 50)$ & & $1(11.2)$ & \\
\hline \multicolumn{8}{|l|}{ Birth type } \\
\hline Vaginal & $0(\% 0)$ & $0(\% 0)$ & & $0(\% 0)$ & & $0(\% 0)$ & \\
\hline C-section & $20(\% 100)$ & $12(\% 100)$ & & $12(\% 100)$ & & $8(\% 100)$ & \\
\hline
\end{tabular}


Corporation, Tokyo, Japan). The number of HPCs were also quantified by Flow cytometry (FACSAriallII). The BD (Becton, Dickinson and Company San Jose, CA 95131 USA) Procount TM Progenitor Cell Count Kit with PE Labeled monoclonal anti-CD34+ antibody was used to determine absolute numbers and percentages of CD34+ cells. Percentages and absolute numbers of CD34+ cells were analyzed by flow cytometry. Our gate strategy was shown in (Figure 1A).

\section{Statistical Analysis}

Descriptive analyzes were used for maternal age, gestational age, birth weight, neonatal gender, birth type in clinical classification. Absolute numbers and percentages of CD34+ cells and HPCs between groups were statistically evaluated using the One Way Anova test on Flow Cytometry and Sysmex XN20 analyzers, respectively. The relationship between Flow Cytometry and Sysmex XN20 was established with the Sperman Correlation test. All data were processed with Graphpad Prism version 8.4.2. P-value $<0.05$ was considered statistically in all analyzes.

\section{Results}

The classification of pregnant women and newborns included in the study and the relevant information regarding maternal age, gestational age, birth weight, gender, and type of birth are summarized in Table 1. All births that we have collected samples from were cesarean. All groups were similar in terms of maternal age and neonatal gender. Compared to the control group, in terms of gestational age and birth weight, significant results were detected. Gestational age was significantly shorter (?) in the MAP group $(p=0.0179)$. The birth weight of infants was significantly lower $(p<0,001)$ in the group of GHT.
MNCs obtained from umbilical cord blood were analyzed with stem cell markers of a hematopoietic precursor. First, CD34+ stem cell percentages were compared. There was no statistically significant difference across groups (Figure 1B). On the other hand, we observed a significant increase $(p<0.05)$ in CD34+ cells count in the GHT and GDM groups compared to controls. The values of the MAP group and the control group were very close and it was not significant (Figure 1B). Lymphocyte numbers were also significantly elevated in the GHT and GDM groups compared to controls $(p<0.05)$ (Figure 1B).

Next, we compared the CD34 staining results obtained from Sysmex XN20 (Automated Hematology Analyzers) to the result of flow cytometry. The HPCs count achieved from Sysmex XN20 were compared with the control group. Although no significant result was found in any disease group, we gained a trend similar to flow cytometry results. Importantly, we had a significant increase in the numbers of lymphocytes measured by Sysmex XN20 compared to the control group in the GHT group $(p<0.05)$, similar to/just as flow cytometry analysis (Figure 2). The differences in the GDM and MAP groups were not significant. The numbers of CD34+ cells, measured by flow cytometry, and HPCs number were compared. There was a significant correlation between the HPC numbers of the control group and the number of CD34+ cells $(p<0.01)$. The Spearman correlation coefficient between the two control groups was $r$ : 0570 . We did not observe a significant correlation between HPCs numbers and CD34+ cell numbers of disease groups of GHT, GDM, MAP. Spearman correlation coefficients and $P$ values were r:0.5727/p:0.0708, r:0.2149/p:0.4779, r:0.111/p:0.779, respectively. Our results are shown in (Figure 3 ).

A
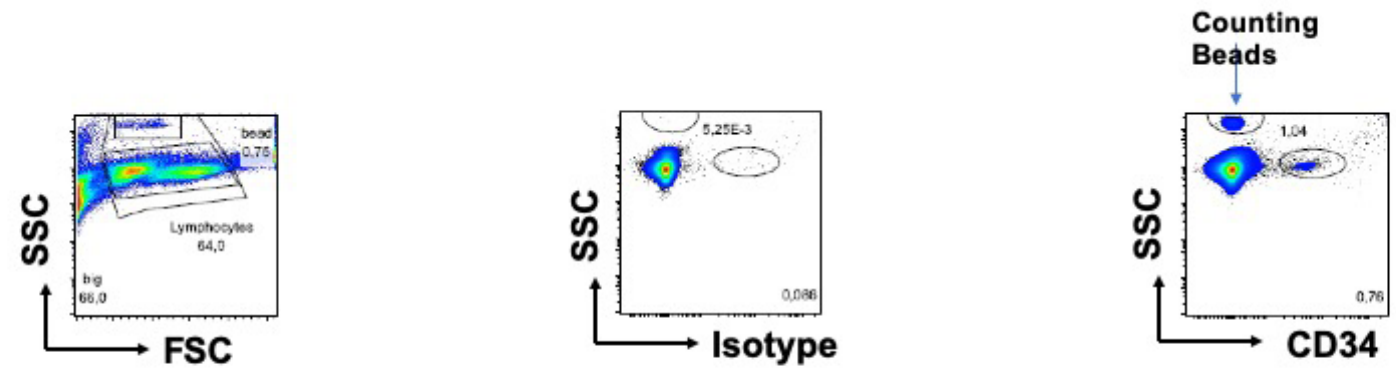

B
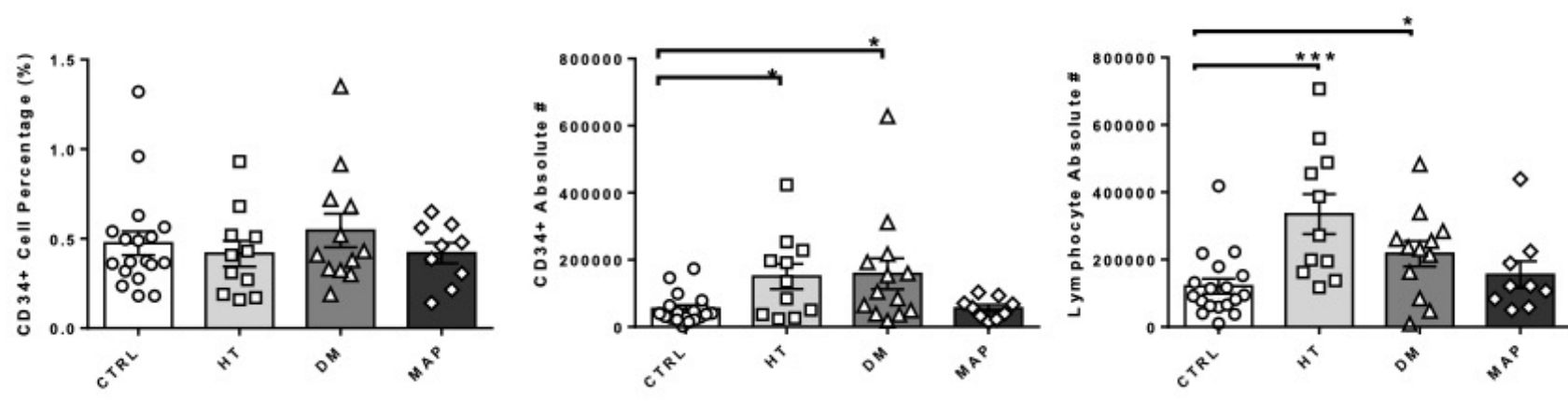

Figure 1. Levels of CD34 + cells and lymphocytes in control, Gestational hypertension, GDM and MAP groups; $p>0.05 ; p<0.001$ 


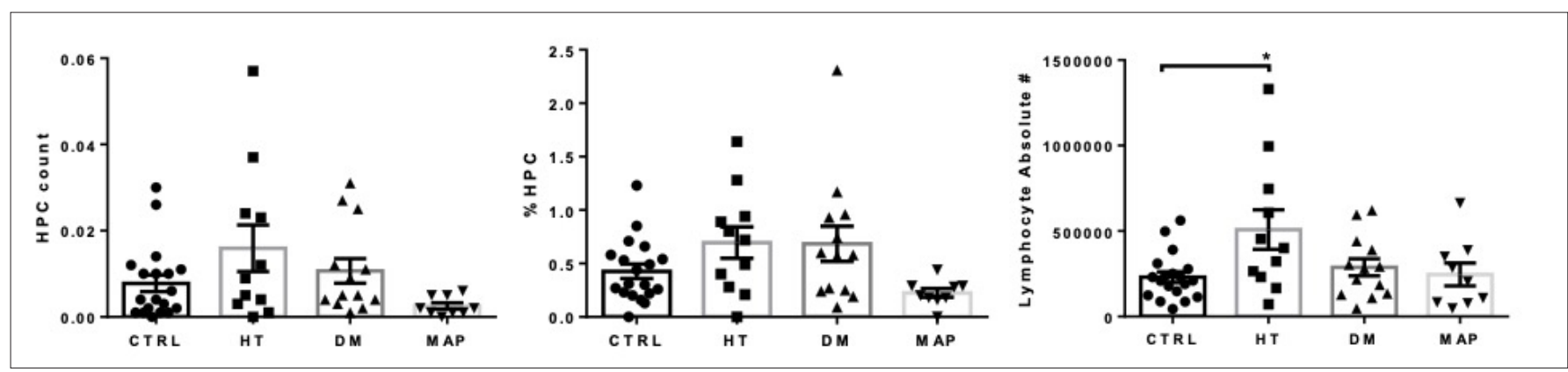

Figure 2. HPCs and lymphocyte level in Control, Gestational hypertension, GDM and MAP groups. p $>0.05$

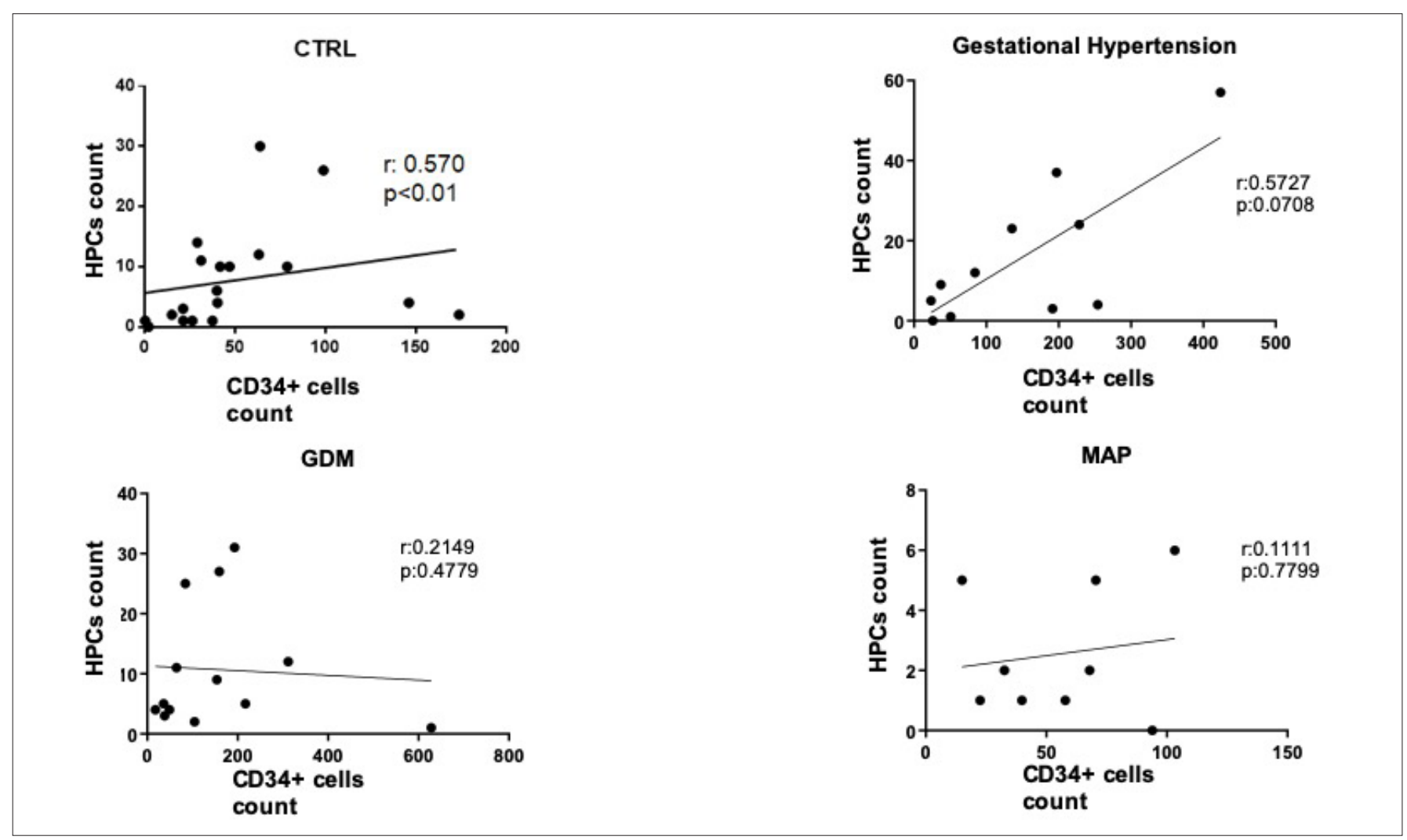

Figure 3. Correlation between HPCs and CD34 + cells. $p>0.05 r$;correlation coefficient

\section{Discussion}

In this study, the effects of GHT, GDM, MAP on CD34+ cell counts, and the correlation between Sysmex XN20 and flow cytometry results were investigated. CD34+ cell percentages between the groups were not statistically significant. However, the GDM and GHT groups had significantly increased CD34+ cells as well as lymphocyte numbers. For the control group, a significant correlation was confirmed between flow cytometry and Sysmex XN20 analysis, but the correlation coefficient was low $(P<0.01, r: 0.579)$. The correlation coefficients between Sysmex XN20 analysis and flow cytometry and of the remaining disease groups were poor ( $r: 0.5727 / p: 0.0708$ for GHT, r:0.2149/p:0.4779 for GDM, r:0.111/p:0.779 for MAP).

As mentioned above, all samples were obtained from a C-section birth, gestational age was significantly shorter in the MAP group, and birth weight was significantly lower in the group of gestational hypertension. Lim et al. ${ }^{17}$ and Dimitriou et al18 showed that type of birth had no significant effect on CD34+ cells in umbilical cord blood. Other studies state that cesarean deliveries have more CD34+ cell contents in the umbilical cord compared to vaginal delivery. ${ }^{19,20} \mathrm{Al}-\mathrm{S} w e e d a n$ et al. ${ }^{11}$ demonstrated normal vaginal delivery was associated with 0.18 times more yield of CD34+ cells compared to cesarean sections in the multivariate model. Cervera et al. ${ }^{21}$ showed that there was not a significant relationship between CD34+ cell numbers and gestational age. Lin et al. ${ }^{22}$ demonstrated elevated CD34+ cells content in premature babies. Ballen et al. ${ }^{10}$ and other investigators 23-25 reported the opposite. Many of the previous reports revealed a positive correlation between birth weight and CD34+ cells count. ${ }^{9-11,16}$ In light of divergent results from several studies, differences between groups should be taken into account when evaluating the results.

The increase of CD34+ cells in the preeclampsia by Benian et al. ${ }^{26}$ and Al-Sweedan et al. ${ }^{11}$ is in line with our results. However, in three previous studies, a decrease in the number of CD34+ cells in the preeclampsia group compared to the non-preeclampsia group was reported. ${ }^{27-29}$ This difference may be due to our population size, which is less than two previous studies. 
Alternatively, although our patient group has pathologies of the same origin, our GHT group includes six pregnancy hypertension and five preeclampsia patients.

Hadarits et al. ${ }^{30}$ evaluated the cord blood of neonates born from mothers with GDM and the cord blood of neonates born from non-diabetic mothers. In concordance with our results, they noted that the neonates of gestational diabetic mothers had proportionally more CD34+ cells in cord blood compared to the control group. They also showed CD34+ cells were proportionally higher in the cord blood of neonates of diabetic mothers who were dietregulated and insulin-regulated.

To our knowledge, This is the first study to investigate the effects of MAP on the number of CD34+ cells in umbilical cord blood. Our study population with MAP consists of placenta accreta, placenta percreta diseases. One reason we could not reach statistically significant results may be the limited size of our study groups. However, this does not lower the specificity of the study, and it guides the literature in the context of the effects of these diseases on CD34+ cell numbers and shows that further studies are needed to determine whether these patients will be good candidates for umbilical cord blood transplantation units. It is noteworthy that cesarean section birth rate is increasing and the incidence of these diseases increases with cesarean section.

In the literature, many publications were using HPCs data measured by the white precursor channel. Furundarena et al. ${ }^{31}$ compared the flow cytometry and Sysmex $\mathrm{XN}$ analysis at different times in the autologous group as pre-apheresis, post apheresis, and a day before apheresis. Correlation coefficients were $\quad(r=.9775), \quad(r=.9285) \quad(r=.5744)$, respectively. The most familiar to our results is the day before the apheresis. Park et al..$^{32}$ in the study conducted in 31 patients with stem cell transplantation, the correlation coefficient between Sysmex $\mathrm{XN}$ and flow cytometry was found $(y=0.548), \quad(y=0.652)$ concerning to the percentage and numbers of CD34+ cells, respectively. These results resemble our findings, thus showed a weak correlation. Additionally, Tanosaki et al. ${ }^{33}$ showed that there is a strong correlation between HPCs and CD34+ cells in pre-apheresis $(R 2=0.919)$ peripheral blood samples and apheresis products $(P=0.729)$. One reason that the correlation coefficient revealed in the above-mentioned publications is higher than our results may be the use of mobilizing agents to increase stem cell production from peripheral blood. Increased number of stem cells in the peripheral blood may help to obtain better correlation. Other reasons may be that our sample population is less than other studies, or that PBMCs isolated from blood are analyzed on the Sysmex XN20 instead of a blood sample directly. Besides, no study comparing flow cytometry analysis with Symex XN20 in the GHT, GDM, and MAP disease group have been published. One of the biggest reasons for not achieving an adequate correlation between the flow and Sysmex results in the disease groups is that our patient population is small, but our study still proves that disease groups with a larger population are needed to understand whether Symex XN20 is a good candidate to demonstrate the content of umbilical cord blood.

\section{Conclusion}

While gestational diabetes and gestational hypertension had a positive effect on CD34+ cells in umbilical cord blood, no change was observed in the MAP group examined by us for the first time, in future studies, especially the MAP group population should be expanded. Correlation between flow cytometry and Sysmex XN 20 is low based on is of diseases and it is needed to be studied in larger groups.

Acknowledgment: We would like to thank all pregnant women who participated in the study and the Erciyes University Genome and Stem Cell Center.

Ethics Committee Approval: The Ethical Committee of Erciyes University, Faculty of Medicine, approved this study (Number: 2018/608).

Informed Consent: Written informed consent was obtained from patients who participated in this study.

Peer-review: Externally peer-reviewed.

Author Contributions: EMT wrote the manuscript. EU, MSK, AE designed the study. EMT, SE, AB, FZO, AO performed experiments. SZU and MSK provided patient samples. All authors read, revised the manuscript. AO and EU provided funding.

Conflict of Interest: The authors have no conflict of interest to declare.

Financial Disclosure: The authors declared that this study has received no financial support.

\section{References}

1. Panch SR, Szymanski J, Savani BN, Stroncek DF. Sources of Hematopoietic Stem and Progenitor Cells and Methods to Optimize Yields for Clinical Cell Therapy. Biol Blood Marrow Transplant. 2017;23:1241-1249. [CrossRef]

2. Cohen $\mathrm{Y}$, Nagler $\mathrm{A}$. Umbilical cord blood transplantation--how, when and for whom? Blood Rev. 2004;18:167-179. [CrossRef]

3. Rocha V, Wagner JE Jr, Sobocinski KA, et al. Graft-versushost disease in children who have received a cord-blood or bone marrow transplant from an HLA-identical sibling. Eurocord and International Bone Marrow Transplant Registry Working Committee on Alternative Donor and Stem Cell Sources. N Engl J Med. 2000;342:1846-1854. [CrossRef]

4. Almici C, Carlo-Stella C, Wagner JE, Mangoni L, Garau D, Rizzoli V. Biologic and phenotypic analysis of early hematopoietic progenitor cells in umbilical cord blood. Leukemia. 1997;11:21432149. [CrossRef]

5. Miura J, Minegishi M, Itoh T, et al. Quality evaluation of umbilical cord blood progenitor cells cryopreserved with a small-scale automated liquid nitrogen system. Cryobiology. 2008;57:178-181. [CrossRef]

6. Aroviita $\mathrm{P}$, Teramo K, Hiilesmaa V, Westman $\mathrm{P}$, Kekomäki R. Birthweight of full-term infants is associated with cord blood CD34+ cell concentration. Acta Paediatr. 2004;93:1323-1329. [CrossRef]

7. Zlopasa G. Prikupljanje stanica umbilikalne krvi [Collection of cord blood cells]. Acta Med Croatica. 2009;63:259-262. [CrossRef]

8. Chao NJ, Emerson SG, Weinberg KI. Stem cell transplantation (cord blood transplants). Hematology Am Soc Hematol Educ Program. 2004;354-371. [CrossRef] 
9. Rowisha MA, El-Shanshory MR, El-Hawary EE, Ahmed AY Altoraky SRM. Impact of maternal and neonatal factors on umbilical cord CD34+ cells. Stem Cell Investig. 2020;7:5. [CrossRef]

10. Ballen KK, Wilson M, Wuu J, et al. Bigger is better: maternal and neonatal predictors of hematopoietic potential of umbilical cord blood units. Bone Marrow Transplant. 2001;27:7-14. [CrossRef]

11. Al-Sweedan SA, Musalam L, Obeidat B. Factors predicting the hematopoietic stem cells content of the umbilical cord blood. Transfus Apher Sci. 2013;48:247-252. [CrossRef]

12. Wahid FS, Nasaruddin MZ, Idris MR, Tusimin M, Tumian NR, Mahdy ZA. Effects of preeclampsia on the yield of hematopoietic stem cells obtained from umbilical cord blood at delivery. J Obstet Gynaecol Res. 2012;38:490-497. [CrossRef]

13. Bhide A, Sebire N, Abuhamad A, Acharya G, Silver R. Morbidly adherent placenta: the need for standardization. Ultrasound Obstet Gynecol. 2017;49:559-563. [CrossRef]

14. Doumouchtsis SK, Arulkumaran S. The morbidly adherent placenta: an overview of management options. Acta Obstet Gynecol Scand. 2010;89:1126-1133. [CrossRef]

15. Uyanıkoğlu $H$, İncebıyık $A$, Turp $A B$, Çakmak $G$, Sak $S$, Hilali NG. Serum Angiogenic and Anti-angiogenic Markers in Pregnant Women with Placenta Percreta. Balkan Med J. 2018;35:55-60. [CrossRef]

16. Shlebak AA, Roberts IA, Stevens TA, Syzdlo RM, Goldman JM, Gordon MY. The impact of antenatal and perinatal variables on cord blood haemopoietic stem/progenitor cell yield available for transplantation. Br J Haematol. 1998;103:1167-1171. [CrossRef]

17. Lim $F T$, van Winsen L, Willemze R, Kanhai $H H$, Falkenburg $\mathrm{JH}$. Influence of delivery on numbers of leukocytes, leukocyte subpopulations, and hematopoietic progenitor cells in human umbilical cord blood. Blood Cells. 1994;20:547-559. [CrossRef]

18. Dimitriou H, Perdikogianni C, Stiakaki E, Vorgia P, Hatzidaki E, Kalmanti M. The impact of mode of delivery and gestational age on cord blood hematopoietic stem/progenitor cells. Ann Hematol. 2006;85:381-385. [CrossRef]

19. Jan $\mathrm{RH}$, Wen $\mathrm{SH}$, Shyr MH, Chiang BL. Impact of maternal and neonatal factors on CD34+ cell count, total nucleated cells, and volume of cord blood. Pediatr Transplant. 2008;12:868-873. [CrossRef]

20. Chandra T, Afreen S, Kumar A, Singh U, Gupta A. Does umbilical cord blood-derived CD34+ cell concentration depend on the weight and sex of a full-term infant?. J Pediatr Hematol Oncol. 2012;34:184-187. [CrossRef]

21. Cervera A, Lillo R, García-Sánchez F, Madero L, Madero R, Vicario $\mathrm{JL}$. Flow cytometric assessment of hematopoietic cell subsets in cryopreserved preterm and term cord blood, influence of obstetrical parameters, and availability for transplantation. Am J Hematol. 2006;81:397-410. [CrossRef]
22. Lin Y, Weisdorf DJ, Solovey A, Hebbel RP. Origins of circulating endothelial cells and endothelial outgrowth from blood. J Clin Invest. 2000;105:71-77. [CrossRef]

23. Nakagawa R, Watanabe T, Kawano Y, et al. Analysis of maternal and neonatal factors that influence the nucleated and CD34+ cell yield for cord blood banking. Transfusion. 2004;44:262-267. [CrossRef]

24. Wyrsch A, dalle Carbonare V, Jansen W, et al. Umbilical cord blood from preterm human fetuses is rich in committed and primitive hematopoietic progenitors with high proliferative and self-renewal capacity. Exp Hematol. 1999;27:1338-1345. [CrossRef]

25. Thilaganathan B, Nicolaides KH, Morgan G. Subpopulations of CD34positive haemopoietic progenitors in fetal blood. $\mathrm{Br} J$ Haematol. 1994;87:634-636. [CrossRef]

26. Benian A, Uzun H, Aydin S, Albayrak M, Uludağ S, Madazli R. Placental stem cell markers in pre-eclampsia. Int J Gynaecol Obstet. 2008;100:228-233. [CrossRef]

27. Qiu L, Onoyama S, Low HP, et al. Effect of preeclampsia on umbilical cord blood stem cells in relation to breast cancer susceptibility in the offspring. Carcinogenesis. 2015;36:94-98. [CrossRef]

28. Wahid FS, Nasaruddin MZ, Idris MR, Tusimin M, Tumian NR, Mahdy ZA. Effects of preeclampsia on the yield of hematopoietic stem cells obtained from umbilical cord blood at delivery. J Obstet Gynaecol Res. 2012;38:490-497. [CrossRef]

29. Surbek DV, Danzer E, Steinmann C, et al. Effect of preeclampsia on umbilical cord blood hematopoietic progenitor-stem cells. Am J Obstet Gynecol. 2001;185:725-729. [CrossRef]

30. Hadarits O, Zóka A, Barna G, et al. Increased Proportion of Hematopoietic Stem and Progenitor Cell Population in Cord Blood of Neonates Born to Mothers with Gestational Diabetes Mellitus. Stem Cells Dev. 2016;25:13-17. [CrossRef]

31. Furundarena JR, Uranga A, Alkorta A, et al. Evaluation of the predictive value of the hematopoietic progenitor cell count using an automated hematology analyzer for CD34+ stem cell mobilization and apheresis product yield. Int J Lab Hematol. 2020;42:170-179. [CrossRef]

32. Park SH, Park CJ, Kim MJ, etal. The new Sysmex XN-2000 automated blood cell analyzer more accurately measures the absolute number and the proportion of hematopoietic stem and progenitor cells than XE-2100 when compared to flow cytometric enumeration of CD34+ cells. Ann Lab Med. 2015;35:146-148. [CrossRef]

33. Tanosaki R, Kumazawa T, Yoshida A, et al. Novel and rapid enumeration method of peripheral blood stem cells using automated hematology analyzer. Int J Lab Hematol. 2014;36:521-530. [CrossRef] 